\title{
FEMALE PSEUDOHERMAPHRODITISM WITH ADRENOCORTICAL FAILURE IN IDENTICAL TWINS
}

\author{
BY \\ SULAMMITH WOLFF \\ From the Paediatric Department, Whittington Hospital, London
}

(RECEIVED FOR PUBLICATION NOVEMBER 25, 1953)

The adrenogenital syndrome of prenatal onset has been described many times, and its association with adrenocortical failure is well known.

Wilkins in 1948 collected 99 cases, of which 16 were male and 83 female. Ten of the male and six of the female cases had associated adrenocortical failure. Since then 35 further cases of this association of syndromes have been reported; 12 were male and 23 female (Allibone, Baar and Cant, 1947; Tepper, 1949; Zuelzer and Blum, 1949; Panos, 1950; Hinman, 1951; Knudson, 1951; Jailer, 1951; Crigler, Silverman and Wilkins, 1952; Doxiadis, 1952).

The condition is known to occur in siblings, but has not previously been described in identical twins.

Of the 51 children with the adrenogenital syndrome and associated adrenocortical failure, only 16 had survived beyond the age of 12 months at the time of reporting. The others died in infancy as a result of adrenocortical failure. Of the 16 children who survived for more than one year, four died at 20 months, $3 \frac{1}{2}$ years, 6 years and 4 years respectively. The others were kept alive by constant medication with salt, D.O.C.A., and, latterly, cortisone, in various combinations. Only one case has been reported in which it was possible to withdraw salt and D.O.C.A. at the age of 14 months without adverse effects (Doxiadis, 1951). The oldest of the survivors was 11 years at the time of reporting (Gardner, Sniffen and Zygmuntowicz, 1950; Butler, Ross and Talbot, 1939).

The twins described here are therefore of interest both as medical curiosities, and as illustrating the problems involved in the management of this condition.

\section{Case Reports}

The babies were born in the Whittington Hospital on July 29, 1952, after an uneventful 37-week pregnancy. The delivery was normal.

Both parents are well, there are three healthy siblings, and there is no family history of genital abnormalities or deaths in the neonatal period.

The first twin, Raphael, weighed $6 \mathrm{lb} .8 \mathrm{oz}$. at birth, and the second, Evelyn, $7 \mathrm{lb} .4 \mathrm{oz}$.

The genital abnormalities were noticed at birth, and consisted of enlargement of the labia majora which were covered with rugose skin, and hypertrophy of the clitoris, which resembled a hypospadic penis. No testicles were felt.

The babies looked alike (Fig. 1), both had a cutis navel, and the placenta and sac were single. Subsequent examination of the blood at the Blood Group Reference Laboratory, the Lister Institute, provided strong supportive evidence for their being identical twins (Table 1).

On the second day of life they were examined by Mr. Innes Williams of The Hospital for Sick Children, Great Ormond Street, who demonstrated a urogenital sinus into which opened the urethra and a vagina of considerable capacity.

In view of this last finding it was felt that the genital abnormality was most probably one of female pseudohermaphroditism due to congenital adrenal hyperplasia, and therefore it was easy to interpret correctly the signs and symptoms of adrenocortical failure when they appeared.

On the fourth day of life Evelyn vomited once but was otherwise well, while Raphael vomited repeatedly, refused feeds and looked pale and dusky. She was therefore given $1 \mathrm{~g}$. of extra salt on that day in the form of normal saline by mouth, and in addition, vomited feeds were replaced with normal saline. However, she continued to vomit.

On the sixth day Raphael weighed $5 \mathrm{lb} .13 \mathrm{oz}$. and was 


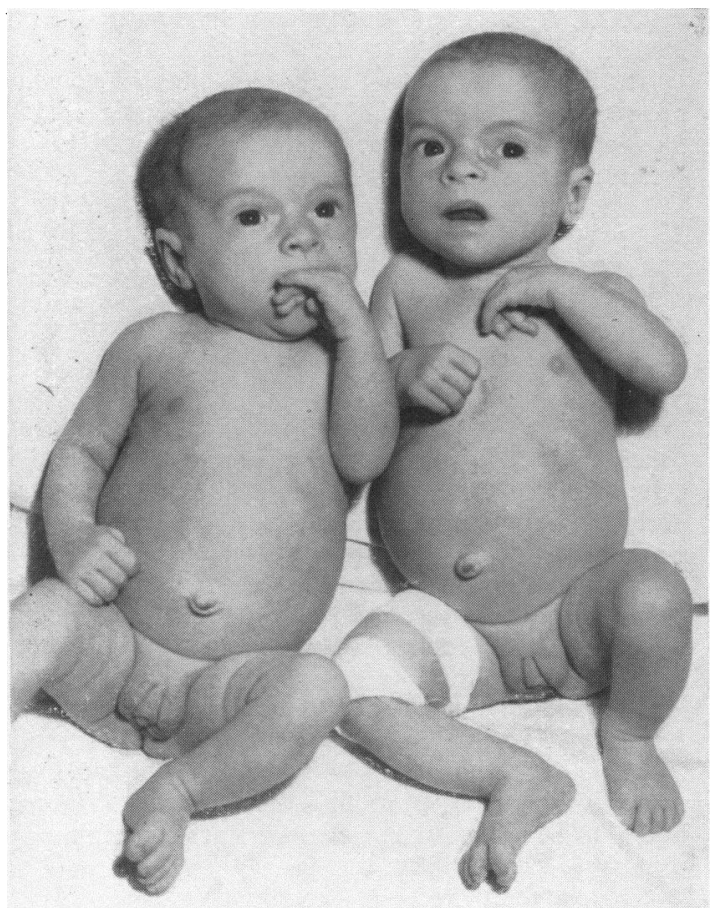

FIG. 1.-. The twins at 3 months.

noticed to have frequent, momentary attacks of pallor and cyanosis, accompanied by pursing of the lips and spasm of the eyelids. Respirations were deep and rapid. Intramuscular D.O.C.A. was therefore also given $(2 \mathrm{mg}$. on the sixth day). Although there was no evidence of infection, a brief prophylactic course of chloromycetin was started. On the seventh day vomiting was less frequent.

The baby's serum electrolytes were as follows:

$\begin{array}{llr}\text { Serum chlorides .. } & \ldots & 531 \mathrm{mg} \text {. per } 100 \mathrm{ml} . \\ \begin{array}{l}\text { Serum potassium } \\ \text { Urinary chlorides }\end{array} & \ldots & 29 \mathrm{mg} \text {. per } 100 \mathrm{ml} \text {. }\end{array}$

On this (the seventh) day Evelyn vomited again and had lost $3 \mathrm{oz}$. in weight, and her serum chloride level was $522 \mathrm{mg}$. per $100 \mathrm{ml}$.

Thereafter both infants were given increasing amounts of salt by mouth, and D.O.C.A. intramuscularly, the dosage being guided by the incidence of vomiting, the eagerness to feed, the state of hydration and the general appearance of the babies (Fig. 2).

On the eighth day Raphael was definitely dehydrated and required subcutaneous fluids which were given as normal saline. Vomiting persisted, however, and on the following day became projectile. She continued to have attacks of pallor and facial spasm, and the temperature rose to $102^{\circ}$.

The dosage of D.O.C.A. was increased with little hesitation since it is known that these babies can tolerate large amounts with impunity (Panos, 1950). The largest doses were given to the twins on their ninth day of life, when Raphael received $9 \mathrm{mg}$. D.O.C.A. as well as $2 \mathrm{ml}$. eucortone and $\frac{2}{3} \mathrm{~g}$. salt (partly as subcutaneous normal saline) and Evelyn received $4 \mathrm{mg}$. D.O.C.A. and $2 \mathrm{~g}$. salt (partly as subcutaneous normal saline). Raphael's serum chloride level on that day was $613 \mathrm{mg}$. per $100 \mathrm{ml}$. and Evelyn's $566 \mathrm{mg}$. per $100 \mathrm{ml}$. Electrocardiograms on both babies were normal.
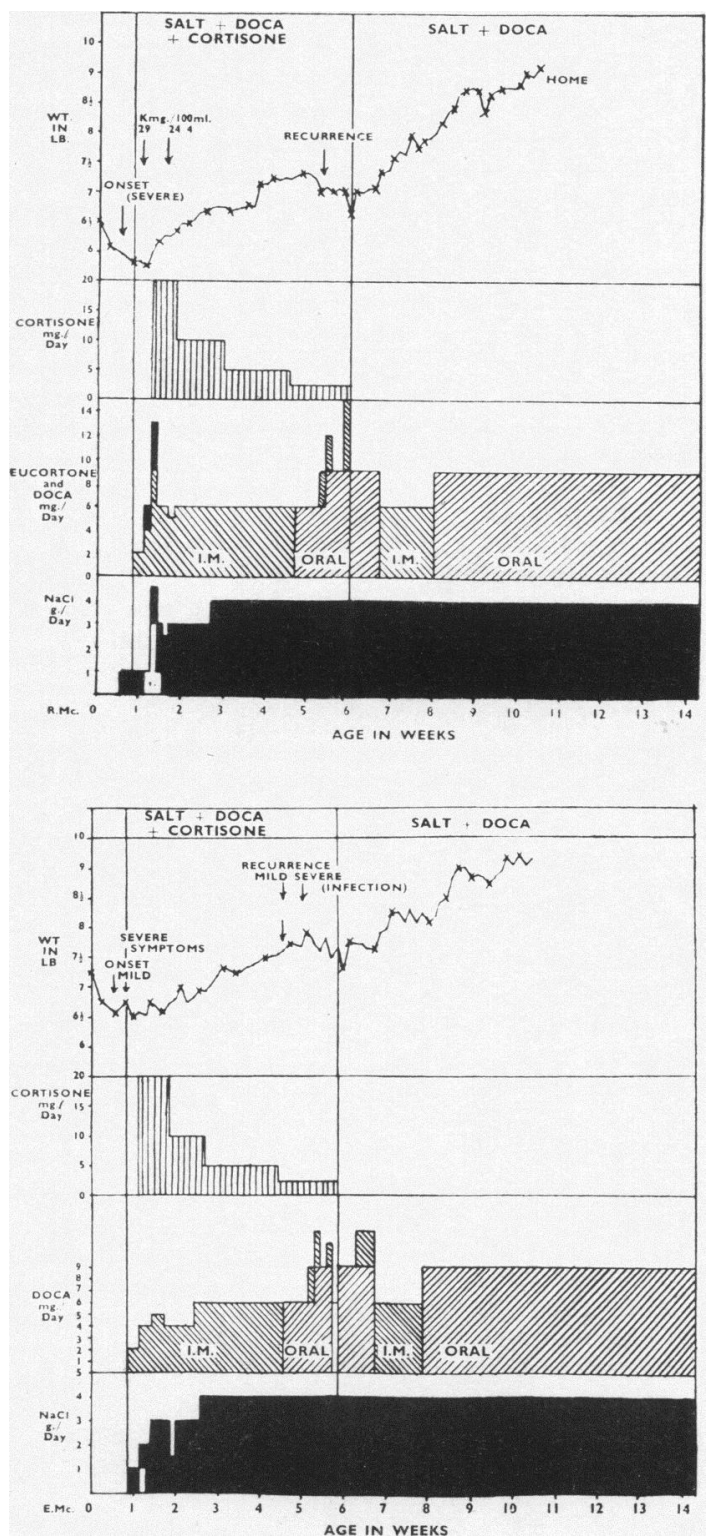

Fig. 2.-Progress charts of Raphael and Evelyn. 
Clinically the electrolyte upset was still not controlled in either twin, the symptoms being much more severe in Raphael.

In view of the increasing amounts of salt and D.O.C.A. required with only temporary clinical improvement, it was decided to give cortisone, and both babies received $20 \mathrm{mg}$. intramuscularly on the evening of the ninth day. By the next morning both had gained weight, and, although still vomiting occasionally, looked very much better. Cortisone, $20 \mathrm{mg}$. daily, was continued for five days, was then gradually reduced and discontinued after 32 days.

Meanwhile the twins were stabilized on $4 \mathrm{~g}$. extra salt per day given as a concentrated solution in the feeds, and $3 \mathrm{mg}$. D.O.C.A. intramuscularly twice daily. Weight gain was satisfactory, and vomiting had ceased. At no time was there evidence of oedema.

Oral D.O.C.A. in the form of sublingual pellets was later substituted for the intramuscular preparation in the same dosage. This resulted in a recurrence of symptoms and additional intramuscular D.O.C.A. had to be given at first. Evelyn, who at that time had a mild upper respiratory infection, was more severely affected. The recurrence of symptoms coincided with the withdrawal of cortisone and may in part have been due to this.

After increasing the dose of oral D.O.C.A. to $9 \mathrm{mg}$. per day the babies remained symptom free and gained weight satisfactorily.

They were discharged home at $2 \frac{1}{2}$ months of age. Progress thereafter was good, but was interrupted in Raphael at 3 months by an episode of vomiting associated with an upper respiratory infection requiring readmission to hospital. The serum chloride level was $449 \mathrm{mg}$. per $100 \mathrm{ml}$. Extra salt and intramuscular D.O.C.A. were given for some days but the baby was subsequently stabilized on the same doses as before and discharged home.

At 5 months the diagnosis was confirmed at The Hospital for Sick Children, Great Ormond Street, by endoscopy under anaesthesia and estimation of the urinary 17-ketosteroids in Raphael. These amounted to $4.85 \mathrm{mg}$. in 24 hours.

Both twins then remained well, and at 7 months Raphael weighed $15 \mathrm{lb} .1 \mathrm{oz}$., and Evelyn $16 \mathrm{lb} .5 \mathrm{oz}$. Both had two teeth and could sit unsupported.

Two weeks later they both developed Sonne dysentery and were admitted to a fever hospital. The progress of the illness was very stormy. The twins were finally transferred to the Gastro-enteritis Unit of the Queen Elizabeth Hospital for Children and, after repeated intravenous therapy and subsequent stabilization on $1 \frac{1}{2} \mathrm{mg}$. intramuscular D.O.C.A. and the equivalent of $4 \mathrm{~g}$. extra salt per day, they were returned to the Whittington Hospital.

Intramuscular D.O.C.A. was gradually changed to the oral preparation in propylene glycol 3 minims t.d.s. (equivalent to $3 . \mathrm{mg}$. per day), and the extra salt intake was increased to $6 \mathrm{~g}$. per day.

At $9 \frac{1}{2}$ months Raphael had a transient recurrence of symptoms requiring a temporary increase in the dosage of D.O.C.A., this time associated with suppurative otitis media.

At 10 months Raphael weighed $14 \mathrm{lb}$. and her blood pressure was $100 / 70 \mathrm{~mm} . \mathrm{Hg}$ and Evelyn weighed $15 \mathrm{lb}$.

$5 \mathrm{oz}$. and had a blood pressure of $90 / 60 \mathrm{~mm}$. $\mathrm{Hg}$.

Serum electrolytes were as follows:

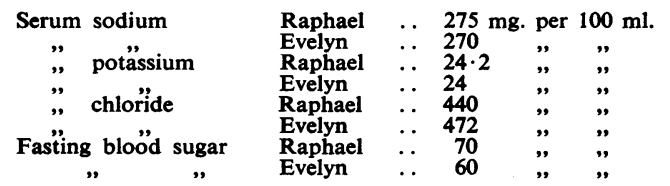

Both twins were well except for hypochromic anaemia, which responded to iron therapy, in Raphael, and for eczema of the face in both, more severe in Raphael. Weights were extremely variable and on the whole stationary.

In order to try to prevent the recurrence of symptoms of adrenocortical insufficiency as a result of possible infections in the future, cortisone was again started, at first intramuscularly in a dosage of $25 \mathrm{mg}$. per day, and later orally in a dosage of $5 \mathrm{mg}$. four times a day. Urinary 17-ketosteroids gradually fell to $1.1 \mathrm{mg}$. in 24 hours and $2 \mathrm{mg}$. in 24 hours in Raphael and Evelyn respectively, and at $10 \frac{1}{2}$ months the twins were discharged home, to be readmitted at intervals for estimation of the urinary 17 -ketosteroids.

Progress thereafter was excellent, and at 12 months Raphael weighed $17 \mathrm{lb}$. and Evelyn $18 \mathrm{lb} .6 \mathrm{oz}$. Both were again sitting without support. Both had six teeth. The bone age was normal. The eczema had completely resolved.

Later, cortisone was increased to $25 \mathrm{mg}$. per day, after which the urinary 17-ketosteroid excretion was 1.3 and $0.9 \mathrm{mg}$. in 24 hours in Raphael and Evelyn respectively. Both babies lost weight and therefore cortisone was reduced to the former dosage of $20 \mathrm{mg}$. per day. Thereafter, weight gain was once more satisfactory.

\section{Discussion}

In these babies cortisone appears to have been the main factor preventing death from adrenocortical failure in the neonatal period. Cortisone was discontinued after one month since it was at first thought possible to maintain the electrolyte balance adequately by the addition of salt and D.O.C.A. alone. It was also thought possible that the deficiency of salt-and-water-regulating hormones might prove to be only temporary as in the case reported by Doxiadis.

At that time it was decided to bring the children up as boys, since is is generally held that these patients, who develop early signs of virilism, adjust better both socially and psychologically if reared as boys from the start (Hinman, 1951).

In view of the frequent reappearance of symptoms of adrenocortical decompensation associated with 
intercurrent infections in these twins, cortisone was given again at 10 months. By analogy with adult cases of Addison's disease, it was thought more possible thereby to prevent future crises. In addition, Crigler et al. (1952) in their detailed study of three cases, have shown that although clinically progress can be satisfactory on salt and D.O.C.A. alone, the serum chemistry cannot be maintained constantly normal without cortisone.

Apart from helping to maintain the electrolyte balance, cortisone suppresses the excessive production of androgenic hormones by the adrenal cortex. The four children so far treated with cortisone have not yet survived long enough for any assessment of its effect on their growth and sexual development. However, in patients with the adrenogenital syndrome alone, cortisone given in adequate doses has been shown to prevent masculinization and excessive bone growth successfully (Wilkins, Crigler, Silverman, Gardner and Migeon, 1952). It is, therefore, probable that the twins will now develop as girls, and if so, plastic surgery to the genitalia will have to be considered in the future.

Wilkins (1948) showed that for adequate suppression of androgenic hormone secretion, the dosage of cortisone should be the minimal amount which will maintain the daily urinary excretion of 17-ketosteroids below $1 \mathrm{mg}$. in infants, and between 1 and $3 \mathrm{mg}$. in children between 1 and 2 years. In the twins it was possible to reduce the daily urinary 17-ketosteroid excretion to $1 \cdot 1$ and $2.0 \mathrm{mg}$. at a daily dosage of $20 \mathrm{mg}$. of oral cortisone, and at the same time to maintain an adequate weight gain. When cortisone was increased to $25 \mathrm{mg}$. per day in an attempt to suppress the secretion of androgens further the babies lost weight. This was taken to be a sign of overdosage, and the amount given was again reduced.

During the initial period of control of the adrenocortical failure with salt and D.O.C.A., and during subsequent phases of adrenocortical decompensation associated with intercurrent infections, the most useful guide to treatment has been the clinical appearance and behaviour of the children. Biochemical estimations were used mainly to confirm the diagnosis of salt-and-water hormone insufficiency. In the day-to-day management of these children it is not justifiable to await results of serum chemistry estimations before initiating treatment.

Vomiting was found to be the first symptom of adrenocortical failure every time. Its cessation and a satisfactory weight chart were reliable evidence of adequate dosage of salt and D.O.C.A.

\section{Summary}

Female pseudohermaphroditism with adrenocortical failure in identical twins is described.

Cortisone was the main factor preventing death in the neonatal period.

Treatment with salt and D.O.C.A. was guided by clinical assessment rather than by biochemical estimations.

When stabilized on salt and D.O.C.A. alone, symptoms of adrenocortical failure reappeared in association with intercurrent infections.

Cortisone was started again and continued, primarily with a view to maintaining more adequately the electrolyte balance, so far with gratifying results.

Cortisone should make it possible for the babies to develop as females.

I should like to thank Mr. Innes Williams for his help in establishing the diagnosis, and Dr. Young and the staff of the Queen Elizabeth Hospital for Children for their expert care of these babies during a very severe illness. I am very grateful to Dr. Dorothy $\mathbf{M}$. Parkin, of the Lister Institute, for the haematological investigations, to Miss Mason for supplying the photograph and reproducing the charts, and to the laboratory and nursing staff of the Whittington Hospital for all their assistance.

Special thanks are due to Dr. Simon Yudkin for permission to publish these cases and for his help in the preparation of this paper.

\section{REFERENCES}

Allibone, E. C., Baar, H. S. and Cant, W. H. P. (1947). Archives of Disease in Childhood, 22, 210.

Butler, A. M., Ross, R. A. and Talbot, N. B. (1939). J. Pediat., 15, 831.

Crigler, J. F., Jr., Silverman, S. H. and Wilkins, L. (1952). Pediatrics, 10, 397.

Doxiadis, S. A. (1952). Proc. roy. Soc. Med., 45, 587.

Gardner, L. I., Sniffen, R. C., Zygmuntowicz, A. S. and Talbot, N. B. Pediatrics, 5, 808.

Hinman, F., Jr. (1951). Amer. Med. Ass., 146, 423.

Jailer, J. W. (1951). Trans. N.Y. Acad. Sci., series 2, 13, 262.

Knudson, A. G. (1951). J. Pediat., 39, 408.

Panos, T. C. (1950). Pediatrics, 5, 972.

Tepper, W. (1949). J. Pediat., 34, 768

Wilkins, L. (1948). Advanc. Pediat., 3, 188. Crigler, J. F., Jr., Silverman, S. H., Gardner, L. I. and Migeon, C. J. (1952), J. Clin. Endocr., 12, 277.

Zuelzer, W. W. and Blum, A. (1949). Pediat., 35, 344. 